\title{
Naphthyl-Naphthalimides as High-Performance Visible Light Photoinitiators for 3D Printing and Photocomposites Synthesis
}

\author{
Mahmoud Rahal ${ }^{1,2,3}$, Bernadette Graff ${ }^{1,2}$, Joumana Toufaily $^{3}{ }^{(D}$, Tayssir Hamieh ${ }^{3,4}{ }^{(}$, Malika Ibrahim-Ouali ${ }^{5}$, \\ Frédéric Dumur ${ }^{6, *(\mathbb{D})}$ and Jacques Lalevée ${ }^{1,2, *}$ \\ 1 Université de Haute-Alsace, CNRS, IS2M UMR 7361, F-68100 Mulhouse, France; \\ mahmoud-rahal@outlook.com (M.R.); bernadette.graff@uha.fr (B.G.) \\ 2 Université de Strasbourg, F-67200 Strasbourg, France \\ 3 Laboratory of Materials, Catalysis, Environment and Analytical Methods (MCEMA), EDST, FS, \\ Lebanese University, P.O. Box 11-2806, Hariri Campus, Hadath, Lebanon; joumana.toufaily@ul.edu.lb (J.T.); \\ t.hamieh@maastrichtuniversity.nl (T.H.) \\ 4 Faculty of Science and Engineering, Maastricht University, P.O. Box 616, 6200 MD Maastricht, \\ The Netherlands \\ 5 Aix Marseille Univ, CNRS, Centrale Marseille, iSm2, F-13397 Marseille, France; malika.ibrahim@univ-amu.fr \\ 6 Aix Marseille Univ, CNRS, ICR UMR 7273, F-13397 Marseille, France \\ * Correspondence: frederic.dumur@univ-amu.fr (F.D.); jacques.lalevee@uha.fr (J.L.)
}

\section{check for}

updates

Citation: Rahal, M.; Graff, B.; Toufaily, J.; Hamieh, T.;

Ibrahim-Ouali, M.; Dumur, F.;

Lalevée, J. Naphthyl-Naphthalimides

as High-Performance Visible Light

Photoinitiators for 3D Printing and Photocomposites Synthesis. Catalysts 2021, 11, 1269. https://doi.org/ $10.3390 /$ catal11111269

Academic Editor: Asuncion Quintanilla

Received: 24 September 2021

Accepted: 20 October 2021

Published: 21 October 2021

Publisher's Note: MDPI stays neutral with regard to jurisdictional claims in published maps and institutional affiliations.

Copyright: (c) 2021 by the authors. Licensee MDPI, Basel, Switzerland. This article is an open access article distributed under the terms and conditions of the Creative Commons Attribution (CC BY) license (https:// creativecommons.org/licenses/by/ $4.0 /)$.

\begin{abstract}
In this article, five new organic dyes based on the naphthalimide scaffold (Napht-1Napht-5) were synthesized and tested as high-performance photoinitiators for both the Free Radical Photopolymerization (FRP) of acrylates and the Cationic Polymerization (CP) of epoxides using blue Light-Emitting Diodes (LEDs) as a safe irradiation source (LED @405 nm and 455). In fact, very good photopolymerization profiles (high final conversions and high polymerization rates) were obtained once these photoinitiators were combined with an Iodonium salt (Iod) or Iod/amine NPG and NVK). Remarkably, these dyes were able to generate interpenetrating polymer networks (IPN) by polymerization of a blend of monomers. These experiments were carried out to improve the polymerization profiles as well as the mechanical properties of the obtained materials. Due to their high photoinitiation abilities, these compounds were used in some applications such as photocomposite synthesis, direct laser write, and 3D printing experiments. To determine the chemical mechanisms, the photochemical/photophysical properties of these compounds were studied using different characterization techniques such as UV-visible absorption spectroscopy, steady-state photolysis, Fluorescence quenching, time-resolved fluorescence spectroscopy, FTIR spectroscopy, and cyclic voltammetry
\end{abstract}

Keywords: naphthalimide; free radical polymerization; cationic polymerization; LED; 3D printing; photocomposites

\section{Introduction}

Nowadays, light-induced cationic (CP) and free radical polymerizations (FRP) are very used and applied in different fields such as radiation curing, coatings [1], printing [2], dentistry [3], cosmetics [4], microelectronics [5], 3D-printing, etc. These processes are booming at the academic and industrial levels due to their numerous advantages compared to the other polymerization techniques, e.g., low energy consumption [6], high spatial resolution [7], and solvent-free processes (no emission of volatile organic compounds) [8]. High performances can also be obtained under mild irradiation conditions [9]. To initiate a photoinduced polymerization, the presence of a light-absorbing system is mandatory. This system receives actinic lights leading to the formation of active species (radicals or cations) which are capable of initiating radicals or cationic photopolymerizations. In this work, we have chosen a series of organic dyes in multicomponent photoinitiating systems (PIS) for both FRP and CP. In order to obtain high quantum yield of initiating species, a 
long lifetime of the photoinitiator excited state $\left(\mathrm{S}_{1}\right.$ or $\left.\mathrm{T}_{1}\right)$ is necessary, allowing an efficient interaction with the additives.

In fact, naphthalimide-based compounds have been used as photoinitiators for both FRP and CP [10-25]. They are characterized by high molar extinction coefficients in the near UV and visible range, long excited state lifetimes and high fluorescence properties. In this study, new naphthalimides (never synthesized before; Scheme 1) have been synthesized and investigated as photoinitiators for Free Radical photopolymerization of acrylate monomers in both thick and thin samples. These compounds are also capable to initiate the cationic polymerization of epoxide functions under blue LEDs as safe irradiation sources [26-29] (405 nm and $455 \mathrm{~nm}$ ). In our work, the five proposed naphthalimides have shown very good photopolymerization profiles of acrylate and epoxide functions in two [Napht/Iod $(0.05 \%-0.1 \% / 1 \%$ w/w)] or three-component [Napht/Iod/NPG $(0.05 \%-0.1 \% / 1 \% / 1 \% w / w / w)]$ PISs using Iodonium salt (Iod) and amine as additives (NPG and NVK). They are able to generate 3D patterned polymers by direct laser write (DLW). Thick glass fiber photocomposites with excellent depth of cure were also obtained using near-UV conveyor (LED@395 nm).

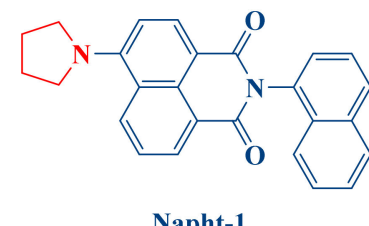

Napht-1

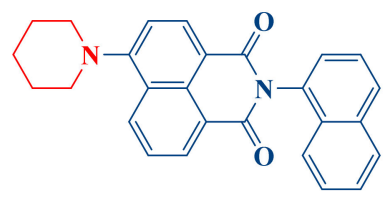

Napht-2

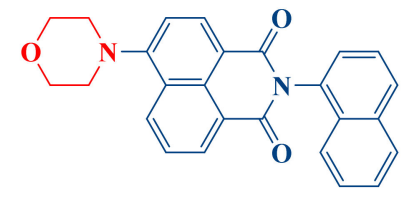

Napht-3

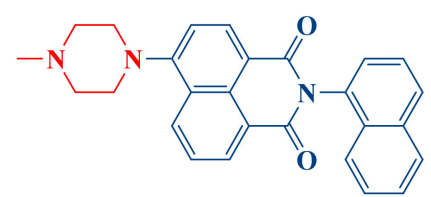

Napht-4

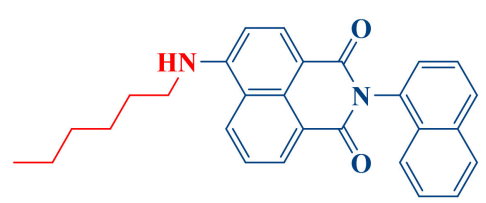

Napht-5

Scheme 1. Chemical structures of the different dyes used in this work.

\section{Results}

2.1. Synthesis of the Investigated Naphthalimides

All details concerning purchased chemicals are given in [30]. Mass spectroscopy analyses were performed as detailed in [31]. Details concerning NMR analyses are given in [32].

2.1.1. Synthesis of 6-Bromo-2-(naphthalen-1-yl)-1H-benzo[de]isoquinoline-1,3(2H)-dione

A mixture 6-bromo- $1 \mathrm{H}, 3 \mathrm{H}$-benzo[de]isochromene-1,3-dione $(2.30 \mathrm{~g}, 8.30 \mathrm{mmol}$, $\mathrm{M}=277.07 \mathrm{~g} / \mathrm{mol})$ and 1-naphthylamine $(1.19 \mathrm{~g}, 8.30 \mathrm{mmol}, \mathrm{M}=143.19 \mathrm{~g} / \mathrm{mol})$ was dissolved in acetic acid (50 mL) and the solution was refluxed overnight. After cooling, the solvent was removed under reduced pressure. The residue was purified by column chromatography $\left(\mathrm{SiO}_{2}\right)$ using a mixture of eluent (DCM:THF). For higher purity, the product was dissolved in a minimum of ethanol and cooled in the fridge for one night. The yellow solid was filtered off, washed with cold ethanol, and dried under vacuum $(2.87 \mathrm{~g}$, $86 \%$ yield). ${ }^{1} \mathrm{H}$ NMR $\left(400 \mathrm{MHz}, \mathrm{CDCl}_{3}\right) \delta: 8.68(\mathrm{dd}, J=8.5,1.0 \mathrm{~Hz}, 1 \mathrm{H}), 8.63(\mathrm{dd}, J=7.3$, $1.0 \mathrm{~Hz}, 1 \mathrm{H}), 8.39(\mathrm{~d}, J=7.9 \mathrm{~Hz}, 1 \mathrm{H}), 8.30(\mathrm{~d}, J=7.9 \mathrm{~Hz}, 1 \mathrm{H}), 8.08(\mathrm{dd}, J=11.4,4.3 \mathrm{~Hz}, 3 \mathrm{H})$, $7.82(\mathrm{~d}, J=8.4 \mathrm{~Hz}, 1 \mathrm{H}), 7.71-7.62(\mathrm{~m}, 2 \mathrm{H}), 7.61-7.55(\mathrm{~m}, 1 \mathrm{H}), 7.46(\mathrm{ddd}, J=8.2,6.8,1.1 \mathrm{~Hz}$, $1 \mathrm{H})) ;{ }^{13} \mathrm{C}$ NMR $\left(101 \mathrm{MHz}, \mathrm{CDCl}_{3}\right) \delta: 163.38,163.31,133.80,132.88,132.58,131.75,131.40$, $131.12,130.06,130.04,129.38,129.19,128.84,128.20,127.04,126.90,126.25,125.71,123.36$, 122.58, 122.54; HRMS (ESI MS) m/z: theor: 401.0051 found: $401.0054\left(\mathrm{M}^{+}\right.$detected). 
2.1.2. Synthesis of 2-(Naphthalen-1-yl)-6-(pyrrolidin-1-yl)-1H-benzo[de]isoquinoline-1,3 (2H)-dione (Napht-1)

A mixture of 6-bromo-2-(naphthalen-1-yl)-1H-benzo[de]isoquinoline-1,3(2H)-dione $(1 \mathrm{~g}, 2.49 \mathrm{mmol}, \mathrm{M}=402.25 \mathrm{~g} / \mathrm{mol})$ was dissolved in 2-ethoxyethanol $(50 \mathrm{~mL})$ and pyrrolidine $(5 \mathrm{~mL})$ was added. The solution was refluxed overnight. After cooling, the solvent was removed under reduced pressure. The residue was filtered on a plug of silicagel using DCM as the eluent. Upon evaporation of the solvent, a precipitate formed. It was filtered off, washed several times with pentane, and dried under vacuum $\left(820 \mathrm{mg}, 84 \%\right.$ yield). ${ }^{1} \mathrm{H}$ $\operatorname{NMR}\left(400 \mathrm{MHz}, \mathrm{CDCl}_{3}\right) \delta: 8.68(\mathrm{dd}, J=8.6,1.1 \mathrm{~Hz}, 1 \mathrm{H}), 8.63(\mathrm{dd}, J=7.3,1.1 \mathrm{~Hz}, 1 \mathrm{H}), 8.49$ $(\mathrm{d}, J=8.6 \mathrm{~Hz}, 1 \mathrm{H}), 7.95(\mathrm{dd}, J=13.6,8.2 \mathrm{~Hz}, 2 \mathrm{H}), 7.67-7.56(\mathrm{~m}, 3 \mathrm{H}), 7.51-7.44(\mathrm{~m}, 2 \mathrm{H}), 7.40$ $(\mathrm{ddd}, J=8.2,6.8,1.3 \mathrm{~Hz}, 1 \mathrm{H}), 6.88(\mathrm{~d}, J=8.7 \mathrm{~Hz}, 1 \mathrm{H}), 3.84(\mathrm{t}, J=6.5 \mathrm{~Hz}, 4 \mathrm{H}), 2.19-2.06(\mathrm{~m}$, $4 \mathrm{H}) ;{ }^{13} \mathrm{C} \mathrm{NMR}\left(101 \mathrm{MHz}, \mathrm{CDCl}_{3}\right)$ 8: 165.16, 164.27, 153.04, 134.57, 133.95, 133.22, 132.51, $132.01,131.61,130.45,129.04,128.56,126.94,126.78,126.13,125.67,123.12,122.80,122.70$, 122.28, 110.52, 108.65, 53.27, 26.09; HRMS (ESI MS) m/z: theor: 392.1525 found: 392.1522 $\left(\mathrm{M}^{+}\right.$detected).

2.1.3. Synthesis of 2-(Naphthalen-1-yl)-6-(piperidin-1-yl)-1H-benzo[de]isoquinoline-1,3 (2H)-dione (Napht-2)

A mixture of 6-bromo-2-(naphthalen-1-yl)-1H-benzo[de]isoquinoline-1,3(2H)-dione $(1 \mathrm{~g}, 2.49 \mathrm{mmol}, \mathrm{M}=402.25 \mathrm{~g} / \mathrm{mol}$ ) was dissolved in 2-ethoxyethanol $(50 \mathrm{~mL})$ and piperidine $(5 \mathrm{~mL})$ was added. The solution was refluxed overnight. After cooling, the solvent was removed under reduced pressure. The residue was filtered on a plug of silicagel using DCM as the eluent. Upon evaporation of the solvent, a precipitate formed. It was filtered off, washed several times with pentane and dried under vacuum $\left(930 \mathrm{mg}, 92 \%\right.$ yield). ${ }^{1} \mathrm{H}$ NMR $\left(400 \mathrm{MHz}, \mathrm{CDCl}_{3}\right) \delta: 8.64(\mathrm{dd}, J=7.3,1.2 \mathrm{~Hz}, 1 \mathrm{H}), 8.57(\mathrm{~d}, J=8.1 \mathrm{~Hz}, 1 \mathrm{H}), 8.49$ $(\mathrm{dd}, J=8.5,1.2 \mathrm{~Hz}, 1 \mathrm{H}), 7.96(\mathrm{dd}, J=11.8,7.9 \mathrm{~Hz}, 2 \mathrm{H}), 7.74(\mathrm{dd}, J=8.4,7.3 \mathrm{~Hz}, 1 \mathrm{H}), 7.63$ $(\mathrm{dd}, J=8.2,7.3 \mathrm{~Hz}, 2 \mathrm{H}), 7.52-7.45(\mathrm{~m}, 2 \mathrm{H}), 7.41(\mathrm{ddd}, J=8.2,6.9,1.4 \mathrm{~Hz}, 1 \mathrm{H}), 7.23(\mathrm{~s}$, 1H), 3.35-3.24 (m, 4H), 1.98-1.87 (m, 4H), 1.81-1.70 (m, 2H); $\left.{ }^{13} \mathrm{C} \mathrm{NMR} \mathrm{(101} \mathrm{MHz,} \mathrm{CDCl}{ }_{3}\right)$ ס: 164.83, 164.30, 157.75, 134.57, 133.27, 132.77, 131.61, 131.12, 130.69, 130.34, 129.24, 128.62, $127.01,126.79,126.55,126.20,125.63,125.49,123.31,122.10,115.94,114.88,54.59,26.27,24.38$; HRMS (ESI MS) m/z: theor: 406.1681 found: 406.1680 ( $\mathrm{M}^{+}$detected).

2.1.4. Synthesis of 6-Morpholino-2-(naphthalen-1-yl)-1H-benzo[de]isoquinoline-1,3 (2H)-dione (Napht-3)

A mixture of 6-bromo-2-(naphthalen-1-yl)-1H-benzo[de]isoquinoline-1,3(2H)-dione $(1 \mathrm{~g}, 2.49 \mathrm{mmol}, \mathrm{M}=402.25 \mathrm{~g} / \mathrm{mol})$ was dissolved in 2-ethoxyethanol $(50 \mathrm{~mL})$ and morpholine $(5 \mathrm{~mL})$ was added. The solution was refluxed overnight. After cooling, the solvent was removed under reduced pressure. The residue was filtered on a plug of silicagel using DCM as the eluent. Upon evaporation of the solvent, a precipitate formed. It was filtered off, washed several times with pentane and dried under vacuum $\left(860 \mathrm{mg}, 85 \%\right.$ yield). ${ }^{1} \mathrm{H}$ NMR $\left(400 \mathrm{MHz}, \mathrm{CDCl}_{3}\right) \delta: 8.66(\mathrm{dd}, J=7.3,1.2 \mathrm{~Hz}, 1 \mathrm{H}), 8.61(\mathrm{~d}, J=8.1 \mathrm{~Hz}, 1 \mathrm{H}), 8.53(\mathrm{dd}$, $J=8.5,1.2 \mathrm{~Hz}, 1 \mathrm{H}), 7.97(\mathrm{dd}, J=12.2,8.2 \mathrm{~Hz}, 2 \mathrm{H}), 7.78(\mathrm{dd}, J=8.5,7.3 \mathrm{~Hz}, 1 \mathrm{H}), 7.67-7.59$ $(\mathrm{m}, 2 \mathrm{H}), 7.53-7.46(\mathrm{~m}, 2 \mathrm{H}), 7.42(\mathrm{ddd}, J=8.2,6.9,1.3 \mathrm{~Hz}, 1 \mathrm{H}), 7.30(\mathrm{~d}, J=8.1 \mathrm{~Hz}, 1 \mathrm{H})$, 4.10-4.01 (m, 4H), 3.38-3.27 (m, 4H); ${ }^{13} \mathrm{C}$ NMR (101 MHz, $\left.\mathrm{CDCl}_{3}\right)$ 8: 164.63, 164.14, 156.09, $134.57,133.13$, 132.60, 131.76, 130.60, 130.58, 130.27, 129.34, 128.67, 127.06, 126.79, 126.42, $126.25,125.99,125.64,123.50,122.01,117.18,115.13,66.99,53.48$; HRMS (ESI MS) m/z: theor: 408.1474 found: 408.1479 ( $\mathrm{M}^{+}$detected).

2.1.5. Synthesis of 6-(4-Methylpiperazin-1-yl)-2-(naphthalen-1-yl)-1H-benzo[de] isoquinoline-1,3(2H)-dione (Napht-4)

A mixture of 6-bromo-2-(naphthalen-1-yl)-1H-benzo[de]isoquinoline-1,3(2H)-dione $(1 \mathrm{~g}, 2.49 \mathrm{mmol}, \mathrm{M}=402.25 \mathrm{~g} / \mathrm{mol})$ was dissolved in 2-ethoxyethanol $(50 \mathrm{~mL})$ and $\mathrm{N}$ methylpiperazine $(5 \mathrm{~mL})$ was added. The solution was refluxed overnight. After cooling, the solvent was removed under reduced pressure. The residue was filtered on a plug of silicagel using DCM as the eluent. Upon evaporation of the solvent, a precipitate formed. 
It was filtered off, washed several times with pentane and dried under vacuum $(944 \mathrm{mg}$, $90 \%$ yield). ${ }^{1} \mathrm{H}$ NMR $\left(400 \mathrm{MHz}, \mathrm{CDCl}_{3}\right) \delta: 8.67(\mathrm{dd}, J=7.3,1.1 \mathrm{~Hz}, 1 \mathrm{H}), 8.61(\mathrm{~d}, J=8.1 \mathrm{~Hz}$, $1 \mathrm{H}), 8.54(\mathrm{dd}, J=8.5,1.1 \mathrm{~Hz}, 1 \mathrm{H}), 7.99(\mathrm{dd}, J=15.7,8.3 \mathrm{~Hz}, 2 \mathrm{H}), 7.78(\mathrm{dd}, J=8.4,7.3 \mathrm{~Hz}$, $1 \mathrm{H}), 7.67-7.63(\mathrm{~m}, 2 \mathrm{H}), 7.51(\mathrm{td}, J=6.9,1.1 \mathrm{~Hz}, 2 \mathrm{H}), 7.44(\mathrm{ddd}, J=8.2,6.9,1.2 \mathrm{~Hz}, 1 \mathrm{H}), 7.32$ $(\mathrm{d}, J=8.1 \mathrm{~Hz}, 1 \mathrm{H}), 3.45-3.36(\mathrm{~m}, 4 \mathrm{H}), 2.83(\mathrm{~s}, 4 \mathrm{H}), 2.50(\mathrm{~s}, 3 \mathrm{H}) ;{ }^{13} \mathrm{C} \mathrm{NMR}\left(101 \mathrm{MHz}, \mathrm{CDCl}_{3}\right)$

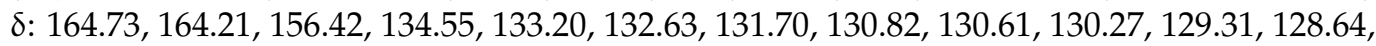
127.05, 126.77, 126.41, 126.24, 125.77, 125.63, 123.39, 122.02, 116.67, 115.14, 55.15, 53.01, 46.14; HRMS (ESI MS) m/z: theor: 421.1790 found: 421.1792 ( $\mathrm{M}^{+}$detected).

2.1.6. Synthesis of 6-(Xexylamino)-2-(naphthalen-1-yl)-1H-benzo[de]isoquinoline-1,3 (2H)-dione (Napht-5)

A mixture of 6-bromo-2-(naphthalen-1-yl)-1H-benzo[de]isoquinoline-1,3(2H)-dione $(1 \mathrm{~g}, 2.49 \mathrm{mmol}, \mathrm{M}=402.25 \mathrm{~g} / \mathrm{mol})$ was dissolved in 2-ethoxyethanol $(50 \mathrm{~mL})$ and hexylamine $(5 \mathrm{~mL})$ was added. The solution was refluxed overnight. The solution was refluxed overnight. After cooling, the solvent was removed under reduced pressure. The residue was filtered on a plug of silicagel using DCM as the eluent. Upon evaporation of the solvent, a precipitate formed. It was filtered off, washed several times with pentane, and dried under vacuum $\left(852 \mathrm{mg}, 81 \%\right.$ yield). ${ }^{1} \mathrm{H} \mathrm{NMR}\left(400 \mathrm{MHz}, \mathrm{CDCl}_{3}\right)$ ) $: 8.65$ (dd, $J=7.3$, $0.8 \mathrm{~Hz}, 1 \mathrm{H}), 8.53(\mathrm{~d}, J=8.4 \mathrm{~Hz}, 1 \mathrm{H}), 8.22-8.12(\mathrm{~m}, 1 \mathrm{H}), 7.95(\mathrm{t}, J=9.0 \mathrm{~Hz}, 2 \mathrm{H}), 7.64(\mathrm{ddd}$, $J=15.6,10.8,7.8 \mathrm{~Hz}, 3 \mathrm{H}), 7.52-7.34(\mathrm{~m}, 3 \mathrm{H}), 6.78(\mathrm{~d}, J=8.5 \mathrm{~Hz}, 1 \mathrm{H}), 5.36(\mathrm{~s}, 1 \mathrm{H}), 3.43(\mathrm{dd}$, $J=11.5,7.1 \mathrm{~Hz}, 2 \mathrm{H}), 1.83(\mathrm{dt}, J=14.8,7.2 \mathrm{~Hz}, 2 \mathrm{H}), 1.50-1.29(\mathrm{~m}, 6 \mathrm{H}), 0.94(\mathrm{t}, J=7.0 \mathrm{~Hz}, 3 \mathrm{H})$; ${ }^{13} \mathrm{C}$ NMR $\left(101 \mathrm{MHz} \mathrm{CDCl}_{3}\right)$ 8: 165.06, 164.42, 150.10, 135.15, 134.53, 133.07, 131.67, 130.63, $130.40,129.08,128.55,126.95,126.75,126.65,126.15,125.61,124.67,123.17,122.15,120.45$, 109.80, 104.40, 43.75, 31.55, 28.83, 26.84, 22.61, 14.04; HRMS (ESI MS) m/z: theor: 422.1994 found: $422.1991\left(\mathrm{M}^{+}\right.$detected).

\subsection{Study of the UV-Visible Spectra of the Different Naphthalimides}

UV-visible absorption spectra of the new studied Naphthalimide dyes were recorded in chloroform and the results are presented in Figure 1. Relevant parameters are summarized in Table 1. In fact, these compounds are characterized by a main absorption band in both the near-UV and the visible range (350-520 nm) with high molar extinction coefficients (e.g., $\varepsilon=16,400 \mathrm{M}^{-1} \mathrm{~cm}^{-1}$ for Napht-1 @444 nm, 11,200 $\mathrm{M}^{-1} \mathrm{~cm}^{-1}$ for Napht-2 @414 nm). On the other hand, high molar extinction coefficients at $405 \mathrm{~nm}$ and $455 \mathrm{~nm}$ are observed for the proposed naphthalimides (e.g., $\varepsilon=6770 \mathrm{M}^{-1} \mathrm{~cm}^{-1} @ 405 \mathrm{~nm}$ and $15,340 \mathrm{M}^{-1} \mathrm{~cm}^{-1}$ @455 nm for Napht-1) which ensures a good overlap with the emission spectra of the LEDs used in FRP, photolysis, and photocomposites synthesis.

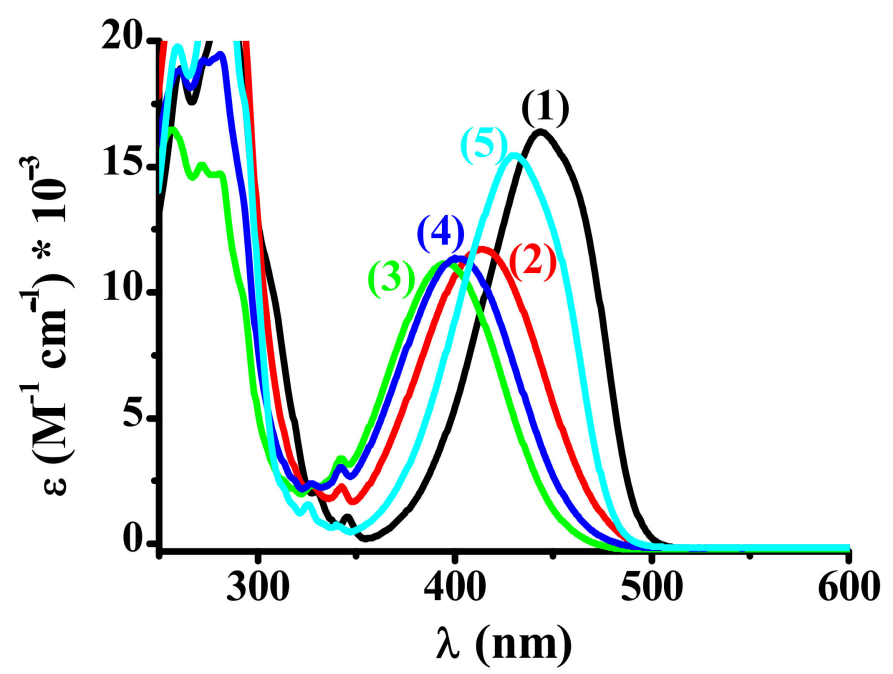

Figure 1. UV-visible absorption spectra of the Naphthalimide derivatives in chloroform: (1) Napht-1, (2) Napht-2, (3) Napht-3, (4) Napht-4, and (5) Napht-5. 
Table 1. Absorption properties of Napht-1-Napht-5 at different wavelengths (405 nm, $455 \mathrm{~nm}, 470 \mathrm{~nm}$ ).

\begin{tabular}{|c|c|c|c|c|c|}
\hline & $\lambda_{\max }(\mathrm{nm})$ & $\varepsilon_{\max }\left(\mathbf{M}^{-1} \mathrm{~cm}^{-1}\right)$ & $\varepsilon_{405 \mathrm{~nm}}\left(\mathrm{M}^{-1} \mathrm{~cm}^{-1}\right)$ & $\varepsilon_{455 \mathrm{~nm}}\left(\mathbf{M}^{-1} \mathrm{~cm}^{-1}\right)$ & $\varepsilon_{470 \mathrm{~nm}}\left(\mathrm{M}^{-1} \mathrm{~cm}^{-1}\right)$ \\
\hline Napht-1 & 444 & 16,400 & 6770 & 15,340 & 11,400 \\
\hline Napht-2 & 414 & 11,200 & 11,250 & 4450 & 1750 \\
\hline Napht-3 & 396 & 11,150 & 10,500 & 890 & 60 \\
\hline Napht-4 & 403 & 11,300 & 11,300 & 1950 & 500 \\
\hline Napht-5 & 430 & 14,200 & 10,360 & 11,000 & 4330 \\
\hline
\end{tabular}

These compounds have a naphthalene group linked by mean of a nitrogen atom of the naphthalimide core, but each dye carries an auxochrome group located at the 6-position of the naphthalimide moiety, so that different absorption properties were obtained. In fact, Napht-1 (which presents a piperidine group) shows a bathochromic shift compared to the others compounds $\left(\lambda_{\max }=444 \mathrm{~nm}\right)$, and Napht-3 (which present a morpholine group) is the most blue shifted $\left(\lambda_{\max }=396 \mathrm{~nm}\right)$ among the other dyes. These differences can be explained by the optimized geometries and the frontier orbitals (Highest Occupied Molecular Orbital (HOMO) and Lowest Unoccupied Molecular Orbital (LUMO)) of the different naphthalimide dyes (See Figure S1).

\subsection{Photopolymerization Experiments Using Different Monomers}

\subsubsection{Free Radical Photopolymerization of Acrylate Monomer (TA)}

The FRP profiles (conversion of acrylates functions vs. irradiation time) are shown in Figure 2 and the different data are summarized in Tables 2 and 3. First, the photopolymerization experiments have been performed using TA as the benchmark acrylate monomer in both thick and thin samples using two or three-component PISs under visible irradiation with a LED @ $405 \mathrm{~nm}\left(\mathrm{I}=110 \mathrm{~mW} / \mathrm{cm}^{2}\right)$ and $455 \mathrm{~nm}\left(\mathrm{I}=75 \mathrm{~mW} / \mathrm{cm}^{2}\right)$. It is important to note, that naphthalimide alone as well as the additives alone (Iod or amine) cannot initiate the FRP in these mild light irradiation conditions. Therefore, iodonium salt and amine are used as coinitiators which are able to interact with the naphthalimide excited states. In fact, Iod/NPG couples show a low initiation ability in FRP of acrylate upon exposure to LED @405 and $455 \mathrm{~nm}$ (Conversion 10\% @405 nm after $60 \mathrm{~s}$ in Thick sample and Conversion $25 \%$ in Thin sample; curves 11 in Figure 2B,D). This result can be assigned to a charge transfer complex (CTC) formation between Iod and NPG. On the other hand, the results show that almost all dyes have the same initiation abilities when thick samples are polymerized and when the dyes are used in two-component PIS based on Napht/Iod $(0.05 \% / 1 \%$ w/w) (e.g., FC = 79\%, 80\% 80\% @405 nm for Napht-1, Napht-2, and Napht-3, respectively). For thick samples, bad polymerization profiles have been obtained (low final conversion and slow polymerization rate) by increasing of the PI concentration. This may be due to an inner filter effect (e.g., FC $=79 \%$ for Napht- $1 / \operatorname{Iod}(0.05 \% / 1 \% w / w)$ vs. $54 \%$ using Napht-1/Iod $(0.1 \% / 1 \% w / w) @ 405 \mathrm{~nm})$. However, good polymerization profiles were recorded using Napht/Iod $(0.1 \%$ or $0.2 \% / 1 \% w / w)$ for thin samples (e.g., FC $=72,70$ and $72 \%$ for Napht-1, Napht-2 and Napht-3, respectively, using Napht/Iod $(0.2 \% / 1 \% w / w)$ vs. $55 \%$ for Napht $-1 / \operatorname{Iod}(0.05 \% / 1 \% w / w))$. 

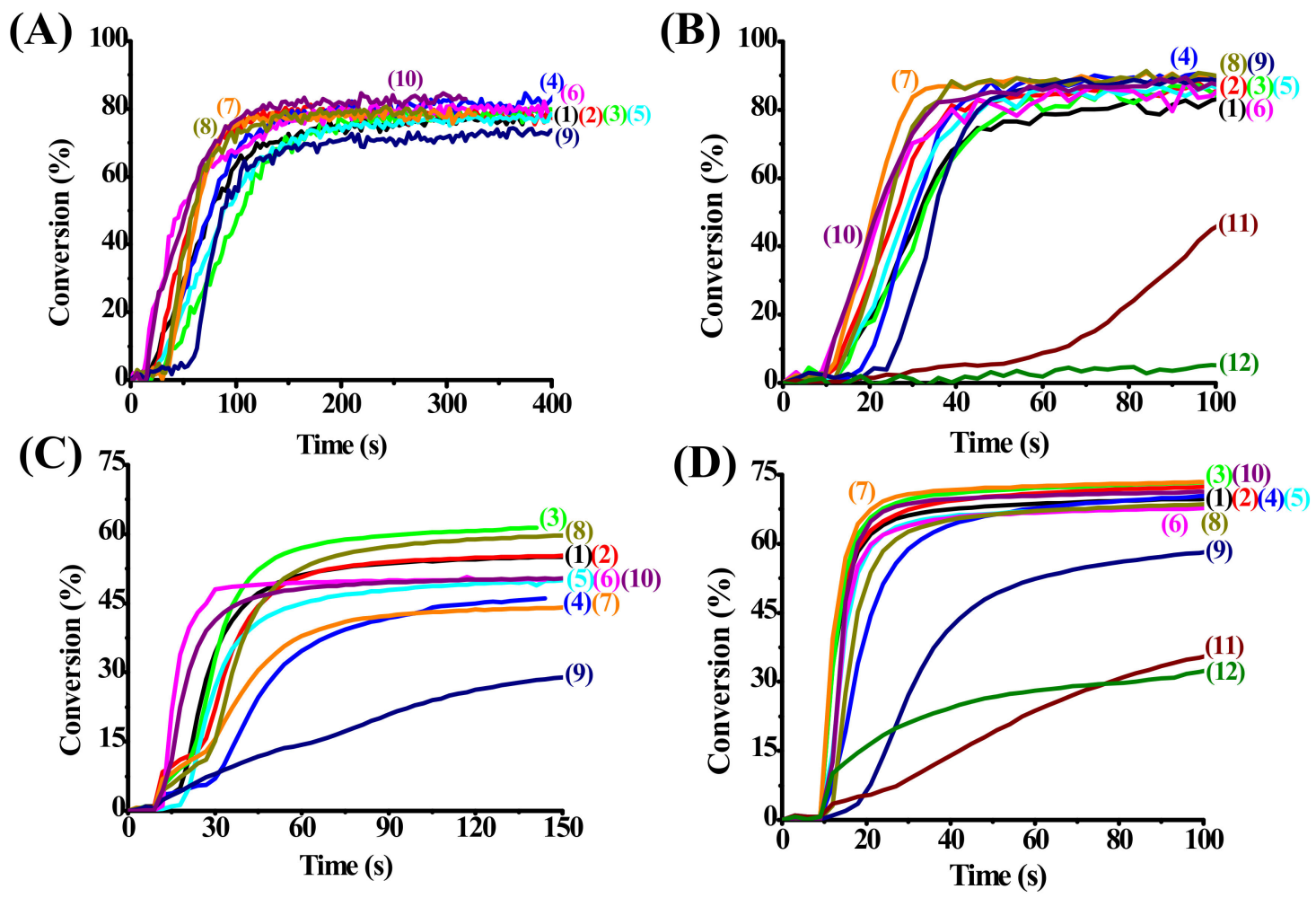

Figure 2. Polymerization profiles of TA (acrylate function conversion vs. irradiation time) in thick samples: (A) using two-component PISs Napht/Iod $(0.05 \% / 1 \% w / w)$; (B) using three-component PISs Napht/Iod/NPG (0.05\%/1\%/1\% $w / w / w)$. In thin samples: (C) two-component PISs Napht/Iod $(0.05 \% / 1 \% w / w) ;(D)$ using three-component PISs Napht/Iod/NPG $(0.05 \% / 1 \% / 1 \% w / w / w)$. Illumination with LED @405 nm: (1) Napht-1, (2) Napht-2, (3) Napht-3, (4) Napht-4, (5) Napht-5, (11) Iod/NPG, Illumination with LED @455 nm: (6) Napht-1, (7) Napht-2, (8) Napht-3, (9) Napht-4, (10) Napht-5, and (12) Iod/NPG $(1 \% / 1 \% w / w)$. Irradiation starts at $\mathrm{t}=10 \mathrm{~s}$.

Table 2. Final reactive function conversions (FC\%) for TA using two-component PISs upon visible light irradiation using the LEDs@405 nm and 455 nm.

\begin{tabular}{|c|c|c|c|c|c|c|c|c|c|c|c|c|}
\hline & \multicolumn{6}{|c|}{ Two-Component PIS: Napht/Iod in Thick Samples } & \multicolumn{6}{|c|}{ Two-Component PIS: Napht/Iod in Thin Sample } \\
\hline & \multicolumn{3}{|c|}{ @405 nm } & \multicolumn{3}{|c|}{$@ 455$ nm } & \multicolumn{3}{|c|}{$@ 405$ nm } & \multicolumn{3}{|c|}{$@ 455$ nm } \\
\hline & $0.05 \%$ & $0.1 \%$ & $0.2 \%$ & $0.05 \%$ & $0.1 \%$ & $0.2 \%$ & $0.05 \%$ & $0.1 \%$ & $0.2 \%$ & $0.05 \%$ & $0.1 \%$ & $0.2 \%$ \\
\hline Napht-1 & $79 \%$ & $70 \%$ & $54 \%$ & $81 \%$ & $72 \%$ & $62 \%$ & $55 \%$ & $53 \%$ & $72 \%$ & $50 \%$ & $65 \%$ & $66 \%$ \\
\hline Napht-2 & $80 \%$ & $79 \%$ & $62 \%$ & $80 \%$ & $76 \%$ & $63 \%$ & $55 \%$ & $67 \%$ & $70 \%$ & $44 \%$ & $60 \%$ & $72 \%$ \\
\hline Napht-3 & $80 \%$ & $37 \%$ & $28 \%$ & $80 \%$ & $90 \%$ & $36 \%$ & $61 \%$ & $69 \%$ & $72 \%$ & $60 \%$ & $56 \%$ & $69 \%$ \\
\hline Napht- 4 & $83 \%$ & $70 \%$ & $54 \%$ & $74 \%$ & $79 \%$ & $72 \%$ & $46 \%$ & $56 \%$ & $68 \%$ & $29 \%$ & $43 \%$ & $63 \%$ \\
\hline Napht-5 & $79 \%$ & $67 \%$ & $62 \%$ & $85 \%$ & $65 \%$ & $60 \%$ & $50 \%$ & $69 \%$ & $70 \%$ & $50 \%$ & $71 \%$ & $69 \%$ \\
\hline
\end{tabular}

Table 3. Final reactive function conversions (FC\%) for TA using three-component PISs upon visible light irradiation using the LEDs@405 nm and 455 nm.

\begin{tabular}{|c|c|c|c|c|}
\hline & \multicolumn{4}{|c|}{ Three-Component PISs: Napht/Iod/NPG $(0.05 \% / 1 \% / 1 \%$ w/w/w) } \\
\hline & \multicolumn{2}{|c|}{ Thick Sample } & \multicolumn{2}{|c|}{ Thin Sample } \\
\hline & $@ 405$ nm & $@ 455$ nm & $@ 405$ nm & $@ 455$ nm \\
\hline Napht-1 & $88 \%$ & $81 \%$ & $77 \%$ & $77 \%$ \\
\hline Napht-2 & $90 \%$ & $88 \%$ & $77 \%$ & $78 \%$ \\
\hline Napht-3 & $88 \%$ & $91 \%$ & $80 \%$ & $78 \%$ \\
\hline Napht-4 & $89 \%$ & $90 \%$ & $79 \%$ & $75 \%$ \\
\hline Napht-5 & $89 \%$ & $76 \%$ & $72 \%$ & $78 \%$ \\
\hline
\end{tabular}


To improve the polymerization profiles, a third component (NPG) was introduced in the photosensitive formulations, and the three-component Napht/Iod/NPG $(0.05 \% / 1 \% / 1 \%$ $w / w / w)$ PISs proved to be more efficient than the two-component PISs e.g., $80 \%$ of the acrylate functions were consumed using the two-component PISs vs. $90 \%$ for the threecomponent PISs.

\subsubsection{Cationic Polymerization}

The cationic polymerization experiments have been performed in thin films upon irradiation with the LEDs @405 nm and $455 \mathrm{~nm}$ using the three-component PISs based on Napht/Iod/NVK $(0.05 \% / 2 \% / 3 \% w / w / w)$. The results are gathered in Figure 3 and Table 4 . In fact, naphthalimide alone, Iod alone, and NVK alone cannot initiate the CP of epoxides, but the combination of Napht/Iod/NVK exhibits a very high efficiency in terms of final epoxy function conversion (e.g., FC $=56 \%$ for Napht- $4 / \operatorname{Iod} / \mathrm{NVK}(0.05 \% / 2 \% / 3 \% w / w / w)$ ). The obtained polymers are characterized by the appearance of a new peak at $\sim 1080 \mathrm{~cm}^{-1}$ ascribed to the polyether network formation (See Figure 3B).

(A)

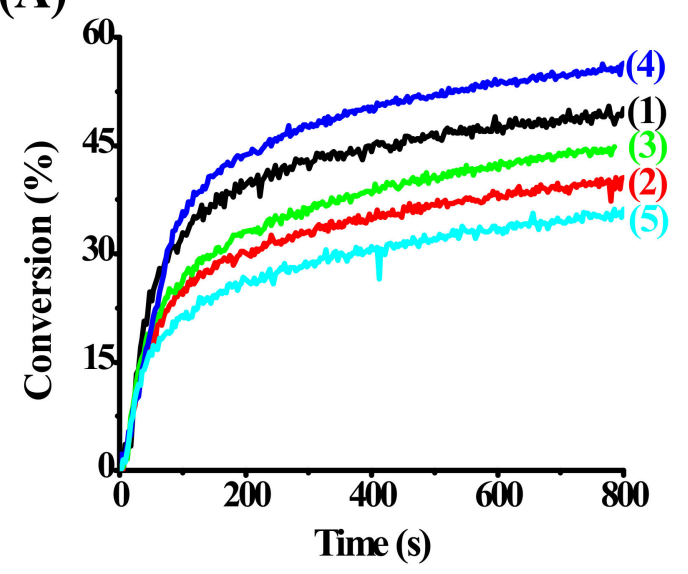

(B)

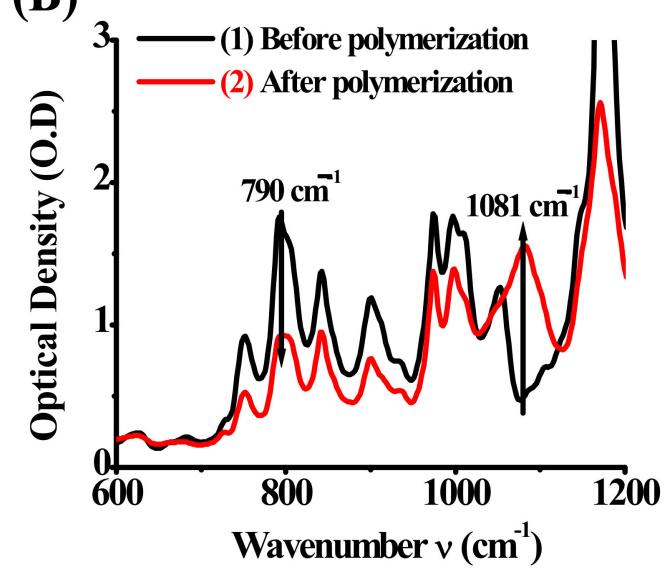

Figure 3. (A) Cationic polymerization (CP) profiles of EPOX (epoxy functions conversion vs. irradiation time) upon exposure to the LED@405 nm using three-component PISs Napht/Iod/NVK $(0.05 \% / 2 \% / 3 \% w / w / w)$. (B) IR spectra recorded before and after polymerization. Irradiation starts at $\mathrm{t}=10 \mathrm{~s}$.

Table 4. Final reactive function conversions (FC\%) for EPOX using three-component PISs upon visible light irradiation using the LED @405 nm.

\begin{tabular}{ccc}
\hline & \multicolumn{2}{c}{ Three-Component PISs: Napht-N/Iod/NVK } \\
\cline { 2 - 3 } & Thick Sample & Thin Sample \\
\hline Napht-1 & $23 \%$ & $50 \%$ \\
Napht-2 & $30 \%$ & $40 \%$ \\
Napht-3 & $42 \%$ & $45 \%$ \\
Napht-4 & $12 \%$ & $56 \%$ \\
Napht-5 & $27 \%$ & $37 \%$ \\
\hline
\end{tabular}

\subsubsection{Interpenetrating Polymer Network (IPN) Synthesis}

Interpenetrating polymer networks are synthesized by initiation of radical and cationic polymerizations simultaneously using TA and EPOX as benchmark acrylate and epoxide monomers. The aim of this study is to improve the photopolymerization profile. In fact, two polymer networks are simultaneously formed, but they are not covalently bonded (just tangled). The obtained results show that the combination of two types of monomers with different functionality leads to a better photopolymerization profile, e.g., the final conversion of acrylate functions was $79 \%$ for Napht- $1 / \operatorname{Iod}(0.05 \% / 1 \% w / w)$ in TA vs. $90 \%$ 
in the TA/EPOX (50\%/50\%) blend. The photopolymerization results are summarized in Table 5.

Table 5. Final conversions (FC\%) of acrylate and epoxide functions using Napht/Iod $(0.05 \% / 1 \%$ $w / w)$ as PIS upon visible light irradiation using different LEDs.

\begin{tabular}{|c|c|c|c|c|}
\hline & \multicolumn{4}{|c|}{ Two-Component PIS: Napht/Iod, TA/EPOX (50\%/50\%) } \\
\hline & \multicolumn{2}{|c|}{ Thick Sample (1.4 mm) } & \multicolumn{2}{|c|}{ Thin Sample $(25 \mu \mathrm{m})$} \\
\hline & $@ 405$ nm & $@ 455$ nm & $@ 405$ nm & $@ 455$ nm \\
\hline Napht-1 & $90 \% / 10 \%$ & $86 \% / 40 \%$ & $88 \% / 30 \%$ & $80 \% / 35 \%$ \\
\hline Napht-2 & $86 \% / 20 \%$ & $92 \% / 35 \%$ & $88 \% / 29 \%$ & $82 \% / 32 \%$ \\
\hline Napht-3 & $90 \% / 20 \%$ & $77 \% / 25 \%$ & $87 \% / 48 \%$ & $81 \% / 35 \%$ \\
\hline Napht-4 & $85 \% / 40 \%$ & $83 \% / 15 \%$ & $82 \% / 54 \%$ & $66 \% / 50 \%$ \\
\hline Napht-5 & $88 \% / 18 \%$ & $80 \% / 10 \%$ & $84 \% / 32 \%$ & $78 \% / 36 \%$ \\
\hline
\end{tabular}

\subsection{Photocomposite Synthesis Using Napht/Iod/NPG (0.05\%/1\%/1\% w/w/w) System}

Composite materials are formed by combining two or more materials with different properties, without dissolving or blending them into each other. Most of the composites are made by taking one material (the matrix) and by surrounding it with fibers or fragments of a stronger material. In our work, thermosetting resins such as TA have been chosen as the polymer matrix and glass fibers have been selected as reinforcement material due to their good costs/performance ratios and their interesting properties (Thermal stability, heat resistance ... ). First of all, glass fibers were impregnated with acrylic resin (50\% glass fiber $/ 50 \%$ organic resin) and then irradiated using a LED conveyor @395 nm. In fact, a very fast curing on the surface was observed with a tack-free character after one pass only using different PISs based on Napht/Iod/NPG $(0.05 \% / 1 \% / 1 \% w / w / w)$. This character is observed at the bottom of the sample but only after some passes (e.g., 5 passes for Napht-1 or 12 passes for Napht-4). The curing results are depicted in Figure 4.

(1)

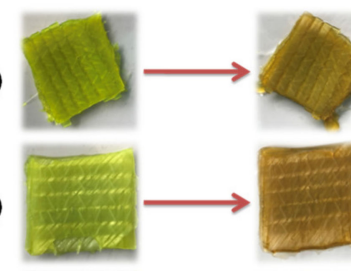

(3)

(4)

(5)

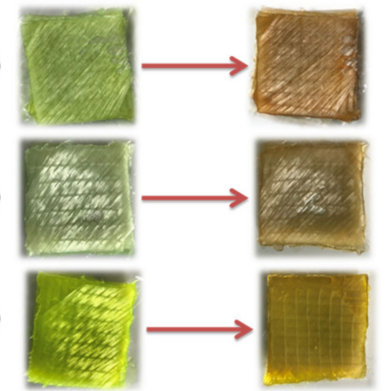

Number of passes to obtained

tack-free surfaces (Surface and bottom):

\section{Surface Bottom Thickness}

5

$4.3 \mathrm{~mm}$

1

6

$4.5 \mathrm{~mm}$

1

9

$4.5 \mathrm{~mm}$

1

12

$4.3 \mathrm{~mm}$

1

5

$4.3 \mathrm{~mm}$

Figure 4. Photocomposites produced by FRP experiments of acrylate monomer (TA) using a LED conveyor @395 nm Napht/Iod/NPG (0.05\%/1\%/1\% w/w/w): (1) Napht-1, (2) Napht-2, (3) Napht-3, (4) Napht-4, and (5) Napht-5.

\subsection{Direct Laser Write (DLW)}

Due to their strong initiation capacity, the different dyes based on naphthalimide were tested for the generation of 3D patterns by FRP of acrylates (for either TA or TMPTA), as 
well as the polymerization of the TA/EPOX blend using a laser diode @405 nm. These experiments were carried out by combining the PI with the iodonium salt and an amine (NPG or TMA) under air. Remarkably, in a very short time ( $2 \mathrm{~min})$, a high thickness is obtained $(\sim 2000 \mu \mathrm{m})$ with smooth surfaces and excellent spatial resolution using Napht$1 / \operatorname{Iod} / \mathrm{TMA}(0.025 \% / 0.5 \% / 0.36 \% w / w / w)$ for example (See Figure 5$)$.
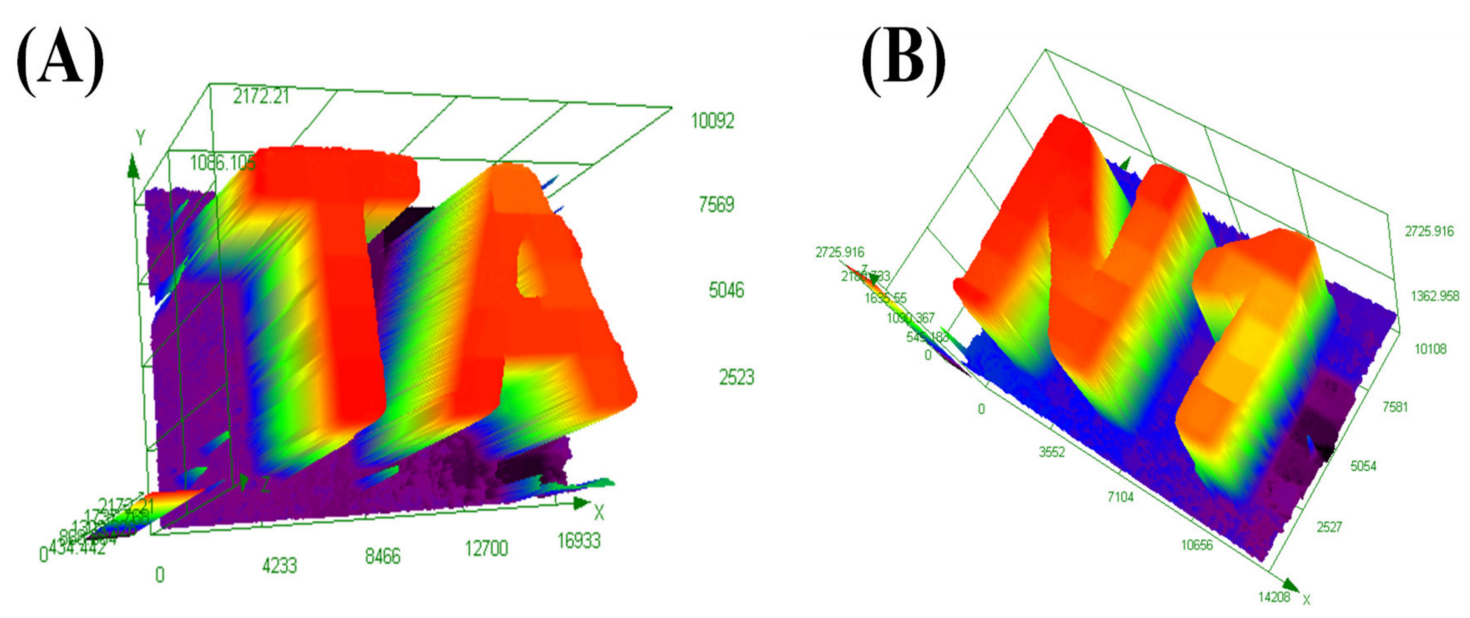

Figure 5. Free radical polymerization experiments by DLW using a laser diode @405 nm for 3D patterns characterized by numerical optical microscopy: (A) Napht-1/Iod/TMA $(0.025 \% / 0.5 \% / 0.36 \%$ w/w/w); (B) Napht-2/Iod/TMA $(0.025 \% / 0.5 \% / 0.42 \% w / w / w)$.

\section{Discussion: Photophysical/Chemical Properties of Naphthalimide Dyes}

In this part, we discuss the photochemical/physical properties of naphthalimides in solution to explain the FRP results obtained, the interaction between dye, Iod, and dye/Iod/amine by several characterization and complementary methods.

\subsection{Steady State Photolysis of Dyes Based Naphthalimides}

Photolysis of the naphthalimides dyes alone, with Iod and in the presence of Iod/NPG couple, can be studied using the UV-visible absorption spectroscopy by following the evolution of the absorption bands, and the photolysis results of Napht-1 are depicted in Figure 6. In fact, a strong and fast decrease of the absorption intensity of Napht1 is observed by combining it with the Iod salt upon irradiation with a LED@405 nm (Figure 6B). This behavior highlights the strong reactivity between the dye and Iod when added. However, a great stability of Napht-1 alone is also evidenced upon irradiation of the solution with a LED@ 405 nm (Figure 6A). On the other hand, a very fast photolysis of Napht-1 with the Iod/NPG couple is also observed upon irradiation, but decrease of the absorption band is much less important than that observed with Iod, e.g., $95 \%$ of Napht-1 is consumed with Iod vs. $80 \%$ with Iod/NPG (Figure 6D curves 2 and 3). This may be due to the regeneration of the dyes in agreement with a photocatalyst behavior. 

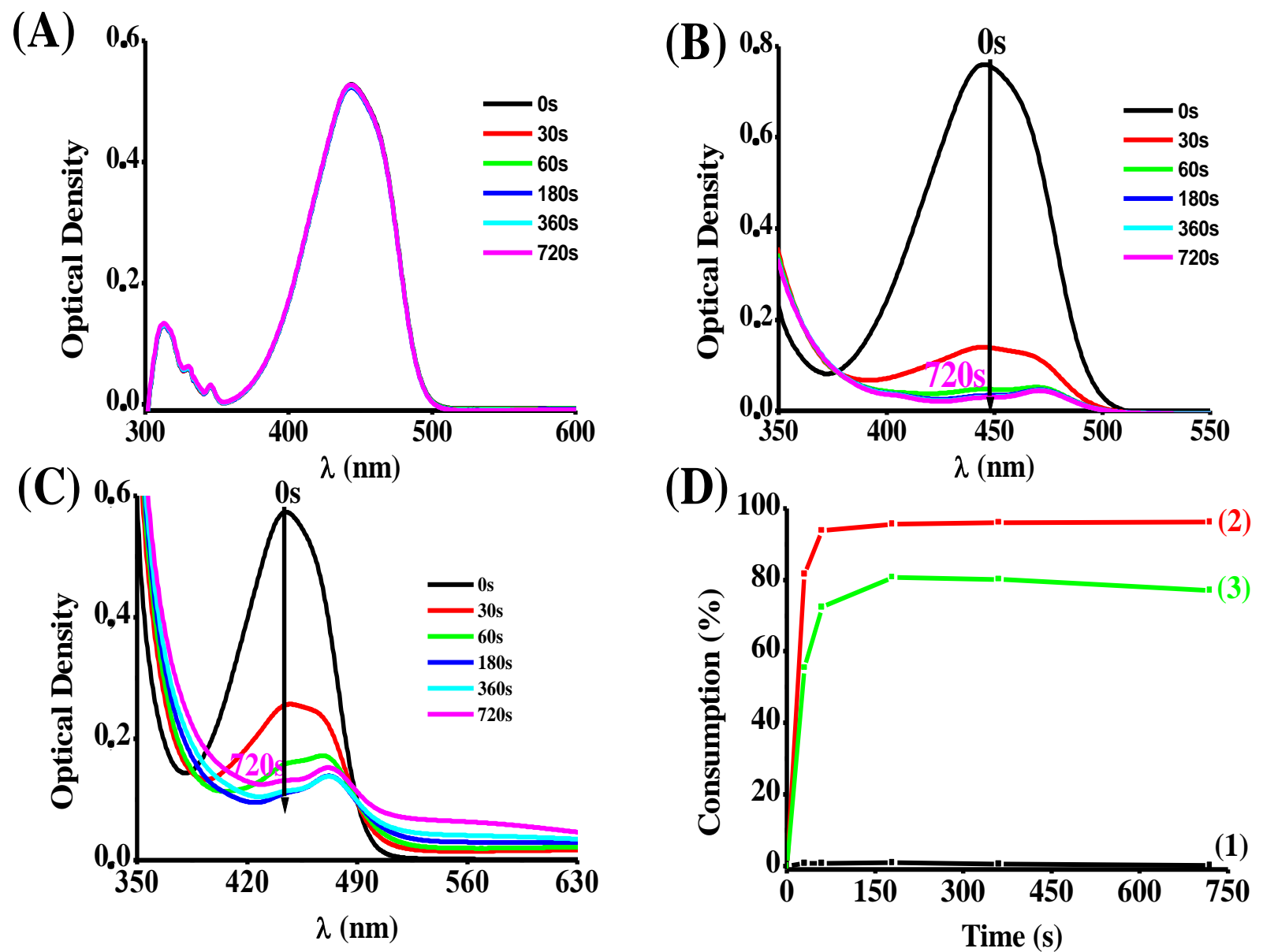

Figure 6. Photolysis experiments of Napht-1 in chloroform: (A) alone, (B) with Iod salt $\left(10^{-2} \mathrm{M}\right)$, and (C) with Iod/NPG $\left(10^{-2} \mathrm{M}\right)$ couple. (D) Consumption percentage of Napht-1: (1) Without additives, (2) With Iod, and (3) With Iod/NPG.

\subsection{Reactivity of the Excited State for the Naphthalimide Compounds}

\subsubsection{Singlet State Properties: Time Resolved Fluorescence}

In this part, $S_{1}$ state is studied according to the fluorescence properties which is examined by time correlated single photon-counting system. In fact, all Naphthalimide compounds have a rather long excited state lifetime (e.g., $\tau=8.53 \mathrm{~ns}, 8.62 \mathrm{~ns}$ and 8.28 for Napht-1, Napht-2, and Napht-3, respectively) and high fluorescence emission properties are observed for these compounds (see Figure 7A,B), except for Napht- 4 which does not exhibit fluorescence properties. This is due to a very low lifetime of its excited state $(\tau=0.5 \mathrm{~ns})$.

\subsubsection{Fluorescence Quenching}

Emission spectra and fluorescence quenching have been carried out in chloroform and the results are reported in Figure 7 (and Figure in Supporting Information). Firstly, a strong decrease of the emission intensity of Napht- 1 is observed when we added an additive (see Figure 7C). This may be due to a strong interaction between the PI and the Iod salt. Based on these experiments, we can therefore calculate the quantum yield of this process which is considered as an important parameter to compare the reactivity of each dye (see for the calculations of this yield in 4.5 below) (See Table 6). In fact, all dyes have almost the same quantum yields (e.g., $\phi=0.55$ for Napht- 1 and Napht-2) except Napht- 4 , where the quantum yield could not be determined (no fluorescence observed). 

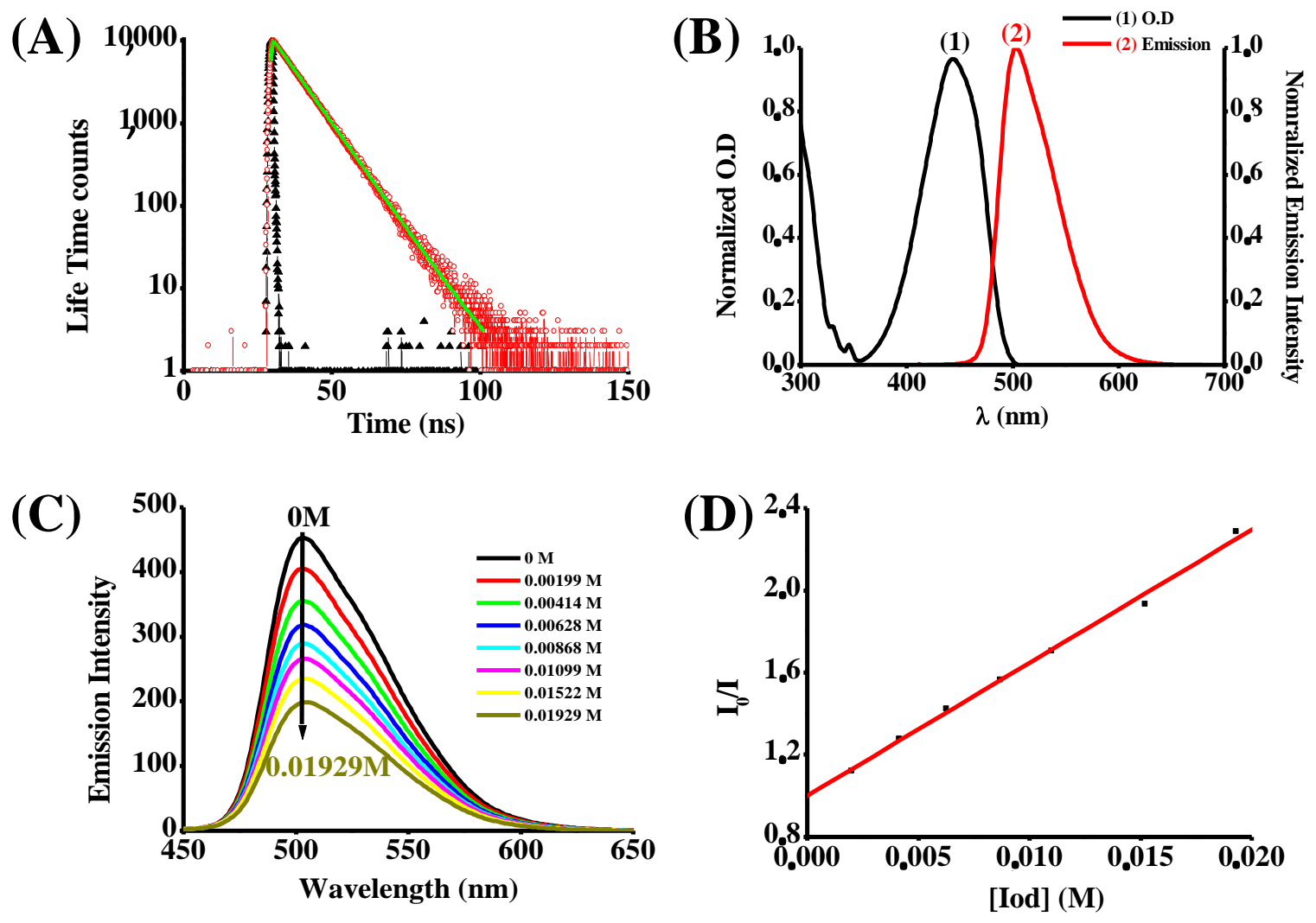

Figure 7. (A) Time-correlated single-photon counting of Napht- 1 in chloroform, $\lambda_{\mathrm{ex}}=367 \mathrm{~nm}, \lambda_{\mathrm{em}}=500 \mathrm{~nm}$, monoexponential curve fitting. (B) $\mathrm{E}_{\mathrm{S} 1}$ determination. (C) Fluorescence quenching of Napht-1 by Iod. (D) Determination of Stern-Volmer coefficient (Ksv).

Table 6. Parameters characterizing the photophysical and photochemical properties of Naphthalimide compounds. For Iod, a reduction potential of $-0.7 \mathrm{eV}$ was used for the $\Delta \mathrm{Get}$ calculations ( $\mathrm{E}_{\mathrm{S} 1}$ stands for the energy of the first excited singlet state).

\begin{tabular}{lcccccc}
\hline & $\mathbf{E}_{\mathbf{0 x}}(\mathbf{e V})$ & $\mathbf{E}_{\mathbf{S 1}}(\mathbf{e V})$ & $\boldsymbol{\Delta G}_{\mathbf{S 1}}(\mathbf{e V})$ & $\mathbf{K s v}$ & $\boldsymbol{\Phi}(\mathbf{P I} / \mathbf{I o d})$ & $\begin{array}{c}\text { Lifetime S1 } \\
\text { (ns) }\end{array}$ \\
\hline Napht-1 & 1.05 & 2.58 & -0.83 & 64.7 & 0.55 & 8.53 \\
Napht-2 & 1.08 & 2.62 & -0.84 & 48.5 & 0.55 & 8.62 \\
Napht-3 & 1.23 & 2.70 & -0.77 & 52 & 0.52 & 8.28 \\
Napht-4 & 1.14 & 2.67 & -0.83 & & & 0.58 \\
Napht-5 & 1.13 & 2.61 & -0.78 & 63 & 0.56 & 9.43 \\
\hline
\end{tabular}

\subsubsection{Chemical Mechanisms}

Therefore, the initiation ability of the new naphthalimides in polymer synthesis can be explained using different characterization techniques based on the behavior of these compounds in the presence of the additives (Iod salt and amine). Thus, a global chemical mechanism can be proposed, based on the photochemical properties of these dyes. Foremost, the photoinitiator excited by the light (LED@ $405 \mathrm{~nm}$ and $455 \mathrm{~nm}$ ) interacts with the iodonium salt thus generating two different radicals ( $\mathrm{Ar}^{\bullet}$ and $\mathrm{Napht}^{+\bullet}$ ) [r1-r2]. In order to improve the polymerization profile, NPG was added to the formulation containing the PI and the Iod salt, thus a charge transfer complex (CTC) formed, which is capable of generating aryl $\left(\mathrm{Ar}^{\bullet}\right)$ initiator radicals [r3-r4]. Then, two radicals (Napht- $\mathrm{H}^{\bullet}$ and $\left.\mathrm{NPG}_{(-\mathrm{H})}{ }^{\bullet}\right)$ are obtained by a hydrogen transfer process from NPG to PI [r5]. In addition, $\mathrm{NPG}_{(-\mathrm{H})}{ }^{\bullet}$ is able to generate of $\mathrm{NPG}_{(-\mathrm{H},-\mathrm{CO} 2)}{ }^{\bullet}$ (intermediate radical) by decarboxylation, this radical leading to the production of reactive species by interaction with the Iod salt ( $\mathrm{Ar}^{\bullet}$ and $\mathrm{NPG}_{(-\mathrm{H}, \mathrm{CO} 2)}{ }^{+}$) [r6-r7]. Finally, the dye can be regenerated (r8-r9). 


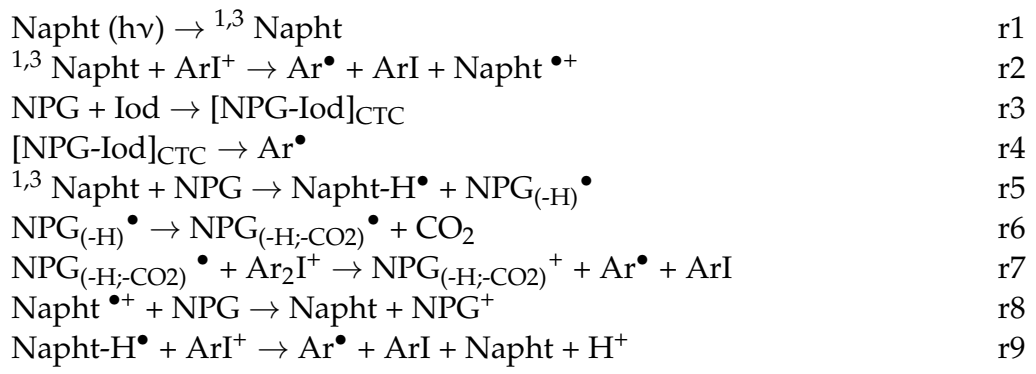

\section{Materials and Methods}

\subsection{Other Chemicals}

All the other chemicals (See Figure 8) were selected with the highest purity available and used as received. The storage inhibitors of the monomers were not removed prior to the experiments. Di-tert-butyl-diphenyl iodonium hexafluorophosphate (Iod) was obtained from Lambson Ltd. (UK). Trimethylolpropane triacrylate (TMPTA) di(trimethylolpropane) tetraacrylate (TA), $N$-phenylglycine (NPG), and N,N-dimethyl- $p$-toluidine (TMA) were obtained from Allnex or Sigma Aldrich. TMPTA, TA, and EPOX were selected as benchmark monomers for the radical and cationic polymerizations.

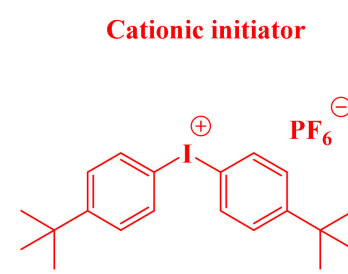

Iod

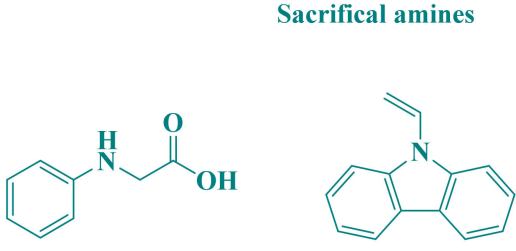

NPG

NVK

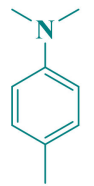

4,N,N-TMA

Monomers<smiles>O=C(OCC1CCC2OC2C1)C1CCC2OC2C1</smiles>

EPOX<smiles>C=CC(=O)OCC(CC)(COC(=O)C=C)COC(=O)C=C</smiles>

TMPTA<smiles>C=CC(=O)OCC(CC)(COCC(CC)(COC(=O)C=C)COC(=O)C=C)COC(=O)C=C</smiles>

TA

Figure 8. Other organic compounds used in this study.

\subsection{Irradiation Sources}

In this paper, light-emitting diodes (LEDs) have been used as safe irradiation sources for different experiments: (1) LED@405 nm $\left(\mathrm{I}_{0}=110 \mathrm{~mW} / \mathrm{cm}^{2}\right)$ for the photopolymerization experiments and the steady state photolysis of Naphthalimide, (2) LED@455 nm $\left(\mathrm{I}_{0}=75 \mathrm{~mW} / \mathrm{cm}^{2}\right)$ for the photopolymerization experiments, and (3) LED conveyor @395 nm $\left(\mathrm{I}_{0}=4 \mathrm{~W} / \mathrm{cm}^{2}\right)$ for the glass fibers photocomposites synthesis.

\subsection{Free Radical Polymerization and Cationic Polymerization Profile Determination Using} Real-Time Fourier Transform Infrared Spectroscopy (RT-FTIR)

In this study, naphthalimide derivatives have been used in two- or three-component photoinitiating systems for both FRP and CP upon LED@405 nm and $455 \mathrm{~nm}$ illumination, based on Napht/Iod $(0.05 \%-0.1 \% / 1 \% w / w)$ and Napht/Iod/amine (NPG and NVK) $(0.05 \% / 1 \% / 1 \% w / w / w)$. In detail, the weight percent of the different chemical compounds (photoinitiators, Iod, and amine) was calculated from the global monomer content. First, the acrylate and epoxy function conversions were continuously followed by real-time FTIR spectroscopy (JASCO FTIR 6600). For the FRP of acrylate monomers (TA or TMPTA) 
which is performed in thick (using a mold about $1.4 \mathrm{~mm}$ ) and thin samples (formulation is sandwiched between two polypropylene films to reduce oxygen inhibition). Evolution of the peak characteristic of the acrylate resin at $6160 \mathrm{~cm}^{-1}$ for the thick sample, and $1630 \mathrm{~cm}^{-1}$ for the thin sample were followed to monitor the polymerization process. On the other hand, consumption of the epoxy functions was followed by the evolution of the peak characteristic of the epoxide group located at $790 \mathrm{~cm}^{-1}$ for the thin sample and $3600 \mathrm{~cm}^{-1}$ for the thick sample [33,34].

\subsection{Redox Potentials and Free Energy Change Calculation}

Redox potentials of naphthalimide derivatives $\left(E_{o x}\right.$ or $\left.E_{\text {red }}\right)$ were determined by cyclic voltammetry experiments using tetrabutylammonium hexafluorophosphate as the supporting electrolyte (potentials vs. Saturated Calomel Electrode-SCE) in acetonitrile $(A C N)$. The free energy change $\left(\Delta G_{e t}\right)$ for an electron transfer reaction was calculated from Equation (1) [35], where $E_{o x}, E_{r e d}, E^{*}$, and $C$ represent the oxidation potential of the electron donor, the reduction potential of the electron acceptor, the excited state energy level (obtained from the crossing point of the absorption and emission spectra) and the coulombic term for the initially formed ion pair, respectively. Here, $\mathrm{C}$ is neglected as usually done for polar solvents.

$$
\Delta \mathrm{G}_{\mathrm{et}}=\mathrm{E}_{\mathrm{ox}}-\mathrm{E}_{\mathrm{red}}-\mathrm{E}^{*}+\mathrm{C}
$$

4.5. Steady State Photolysis, UV-Visible Absorption, Fluorescence Spectroscopy, and Time-Resolved Fluorescence Spectroscopy Experiments

The absorption properties (UV-visible absorption spectrum, molar extinction coefficient) and the steady-state photolysis of the different organic dyes have been determined using a JASCO V730 UV-visible spectrometer. On the other hand, a JASCO FP6200 spectrofluorimeter was used to determine the luminescence properties in solution, and their fluorescence quenching behavior. The electron transfer quantum yields $(\varphi)$ for the PI quenched by Iod salt in chloroform could be calculated based to the classical Stern-Volmer treatment $\left(\mathrm{I}_{0} / \mathrm{I}=1+\mathrm{kq} \tau_{0}[\mathrm{Iod}]\right)$, where $\mathrm{I}_{0}$ and I stand for the fluorescent intensity of Naphthalimide in the absence and the presence of Iod with the following equation: $\phi=\left(\mathrm{kq} \tau_{0}[\operatorname{Iod}]\right) /\left(1+\mathrm{kq} \tau_{0} \mathrm{kq} \tau_{0}[\operatorname{Iod}]\right)[10] . \tau_{0}$ corresponds to the fluorescence lifetime determined using a time-correlated single-photon counting system (HORIBA ${ }^{\circledR}$ Delta Flex with a HORIBA ${ }^{\circledR}$ PPD-850 as detector; the excitation source is a HORIBA ${ }^{\circledR}$ nano LED-370 with an excitation wavelength of $367 \mathrm{~nm}$ and a pulse duration inferior to $1.4 \mathrm{~ns}$ ). The fluorescence intensity decay profiles were recorded in DCM in a quartz cell. A silica colloidal solution LUDOX ${ }^{\circledR}$ was used to evaluate the impulse response function (IRF) of the apparatus.

\subsection{Computational Procedure}

Molecular orbital calculations were achieved with the Gaussian 09 suite of programs [36,37]. Electronic absorption spectra of Napht- 1 to Napht-5 were calculated with the time-dependent density functional theory at the MPW1PW91-FC /6-31G* level of theory on the relaxed geometries calculated at the UB3LYP/6-31G* level of theory.

\subsection{Near-UV Conveyor Experiments: Photocomposites Synthesis}

Photosensitive resins were deposited on the glass fibers which were used for the reinforcement. Curing of the deposited resins was carried out using an LED conveyor @ $395 \mathrm{~nm}\left(4 \mathrm{~W} / \mathrm{cm}^{2}\right)$. Distance between the belt and the LED was fixed to $15 \mathrm{~mm}$, and the belt speed was fixed at $2 \mathrm{~m} / \mathrm{min}$ ( $3 \mathrm{~s}$ of irradiation per pass).

\subsection{D Printing Experiments and Direct Laser Write (DLW)}

3D patterns were obtained using a computer-controlled diode laser at $405 \mathrm{~nm}$ (spot size $=50 \mu \mathrm{m}$ ), which were achieved under air and analyzed by a numerical optical microscope (DSX-HRSU from OLYMPUS Corporation) [38]. 


\section{Conclusions}

Finally, new dyes based on the naphthalimide scaffold have been designed and synthesized in this study. These compounds have been proposed as highly efficient visible light PISs for the free radical photopolymerization of acrylate monomers (TA). Remarkably, high performances were obtained during the photopolymerization experiments when these dyes were used in two or three-component PISs. Due to their strong initiation ability, these derivatives have been tested for the generation of 3D patterns and the synthesis of thick glass fiber photocomposites. The high initiation capacity of these dyes was explained by the very high molar extinction coefficients in the near-UV and visible range, their strong interactions with the additives and their long-excited state lifetime. Water soluble naphthalimides will be investigated in forthcoming works for water soluble PISs.

Supplementary Materials: The following are available online at https:/ /www.mdpi.com/article/ 10.3390/catal11111269/s1. 1H and 13C NMR spectra; Contour plots of HOMOs and LUMOs for Napht-1 to Napht-5. Figure S1. Contour plots of HOMOs and LUMOs for Napht-1 to Napht-5; structures optimized at the B3LYP/6-31G* level of theory.

Author Contributions: Conceptualization, J.L. and F.D.; methodology, J.L. and F.D.; software, B.G.; validation, all authors; formal analysis, all authors; investigation, M.R.; resources, J.L., F.D., M.I.-O.; J.T. and T.H.; writing—original draft preparation, M.R., B.G., F.D., M.I.O. and J.L.; writing-review and editing, all authors; supervision, J.L., F.D., J.T. and T.H.; project administration, J.L., F.D., J.T. and T.H.; funding acquisition, J.L., F.D., J.T. and T.H. All authors have read and agreed to the published version of the manuscript.

Funding: This research was funded by The Association of Specialization and Scientific Guidance, the Centre National de la Recherche Scientifique, Aix Marseille Université and the Université de Haute Alsace. This research was also funded by the Agence Nationale de la Recherche (ANR agency) through the PhD grant of Guillaume Noirbent (ANR-17-CE08-0054 VISICAT project).

Data Availability Statement: The data presented in this study are available on request from the corresponding author.

Acknowledgments: The Lebanese group would like to thank "The Association of Specialization and Scientific Guidance" (Beirut, Lebanon) for funding and supporting this scientific work. Aix Marseille University and the Centre National de la Recherche Scientifique (CNRS) are acknowledged for financial support.

Conflicts of Interest: The authors declare no conflict of interest. The funders had no role in the design of the study; in the collection, analyses, or interpretation of data; in the writing of the manuscript; or in the decision to publish the results.

\section{References}

1. Wu, L.; Baghdachi, J. Functional Polymer Coatings: Principles, Methods, and Applications; Wiley Series on Polymer Engineering and Technology; Wiley: New York, NY, USA, 2015.

2. Lawrence, J.; O’Neill, F.; Sheridan, J. Photopolymer holographic recording material. Optik 2001, 112, 449-463. [CrossRef]

3. Bouzrati-Zerelli, M.; Maier, M.; Dietlin, C.; Morlet-Savary, F.; Fouassier, J.P.; Klee, J.E.; Lalevée, J. A novel photoinitiating systemproducing germyl radicals for the polymerization of representative methacrylate resins: Camphorqui-none/R3GeH/iodonium salt. Dent. Mater. 2016, 32, 1226-1234. [CrossRef]

4. Morgan, S.E.; Havelka, K.O.; Lochhead, R.Y. Cosmetic Nanotechnology: Polymers and Colloids in Cosmetics in Person Care; ACS Symposium Series; American Chemical Society: Washington, DC, USA, 2007; p. 961.

5. Drobny, J.G. Radiation Technology for Polymers; CRC Press: Boca Raton, FL, USA, 2003.

6. Xie, C.; Leng, K.; Sheng, J.; Wang, X.; Li, Q.; Song, L.; Liu, L.; Sun, H.; Yu, Q. Preparation of poly(methyl methacrylate) micro-spheres via photopolymerization initiated by LED light source. Colloid. Polym. Sci. 2020, 298, 1285-1291. [CrossRef]

7. Corrigan, N.; Yeow, J.; Judzewitsch, P.; Xu, J.; Boyer, C. Seeing the Light: Advancing Materials Chemistry through Photopolymerization. Angew. Chem. Int. Ed. 2019, 58, 5170-5189. [CrossRef]

8. Yilmaz, G.; Yagci, Y. Photoinduced metal-free atom transfer radical polymerizations: State-of-the-art, mechanistic aspects and applications. Polym. Chem. 2018, 9, 1757-1762. [CrossRef]

9. Tasdelen, M.A.; Lalevée, J.; Yagci, Y. Photoinduced free radical promoted cationic polymerization 40 years after its discovery. Polym. Chem. 2019, 11, 1111-1121. [CrossRef] 
10. Rahal, M.; Mokbel, H.; Graff, B.; Pertici, V.; Gigmes, D.; Toufaily, J.; Hamieh, T.; Dumur, F.; Lalevée, J. Naphthalimide-Based Dyes as Photoinitiators under Visible Light Irradiation and their Applications: Photocomposite Synthesis, 3D printing and Polymerization in Water. ChemPhotoChem. 2021, 5, 476-490. [CrossRef]

11. Bonardi, A.-H.; Zahouily, S.; Dietlin, C.; Graff, B.; Morlet-Savary, F.; Ibrahim-Ouali, M.; Gigmes, D.; Hoffmann, N.; Dumur, F.; Lalevée, J. New 1,8-Naphthalimide Derivatives as Photoinitiators for Free-Radical Polymerization Upon Visible Light. Catalysts 2019, 9, 637. [CrossRef]

12. Zhang, J.; Zivic, N.; Dumur, F.; Xiao, P.; Graff, B.; Fouassier, J.P.; Gigmes, D.; Lalevée, J. Naphthalimide-tertiary amine deriva-tives as blue-light-sensitive photoinitiators. ChemPhotoChem 2018, 2, 481-489. [CrossRef]

13. Xiao, P.; Dumur, F.; Zhang, J.; Graff, B.; Gigmes, D.; Fouassier, J.P.; Lalevée, J. Naphthalimide Derivatives: Substituent Effects on the Photoinitiating Ability in Polymerizations under Near UV, Purple, White and Blue LEDs (385, 395, 405, 455, or 470 nm). Macromol. Chem. Phys. 2015, 216, 1782-1790. [CrossRef]

14. Zivic, N.; Bouzrati-Zerrelli, M.; Villotte, S.; Morlet-Savary, F.; Dietlin, C.; Dumur, F.; Gigmes, D.; Fouassier, J.P.; Lalevée, J. A novel naphthalimide scaffold based iodonium salt as a one-component photoacid/photoinitiator for cationic and radical polymerization under LED exposure. Polym. Chem. 2016, 7, 5873-5879. [CrossRef]

15. Zhang, J.; Dumur, F.; Xiao, P.; Graff, B.; Bardelang, D.; Gigmes, D.; Fouassier, J.-P.; Lalevée, J. Structure design of naph-thalimide derivatives: Towards versatile photo-initiators for near UV/Visible LEDs, 3D printing and water-soluble photoiniti-ating systems. Macromolecules 2015, 48, 2054-2063. [CrossRef]

16. Noirbent, G.; Dumur, F. Recent advances on naphthalic anhydrides and 1,8-naphthalimide-based photoinitiators of polymerization. Eur. Polym. J. 2020, 132, 109702. [CrossRef]

17. Zhang, J.; Zivic, N.; Dumur, F.; Xiao, P.; Graff, B.; Fouassier, J.-P.; Gigmes, D.; Lalevée, J. N-[2-(dimethylamino)ethyl]-1,8naphthalimide derivatives as photo-initiators under LEDs. Polym. Chem. 2018, 9, 994-1003. [CrossRef]

18. Xiao, P.; Dumur, F.; Zhang, J.; Graff, B.; Gigmes, D.; Fouassier, J.-P.; Lalevée, J. New role of aminothiazonaphthalimide deriv-atives: Outstanding photoinitiators for cationic and radical photopolymerizations under visible LEDs. RSC Adv. 2016, 6, 48684-48693. [CrossRef]

19. Zivic, N.; Zhang, J.; Bardelang, D.; Dumur, F.; Xiao, P.; Jet, T.; Versace, D.-L.; Dietlin, C.; Morlet-Savary, F.; Graff, B.; et al. Novel naphthalimide-amine based photoinitiators operating under violet and blue LEDs and us-able for various polymerization reactions and synthesis of hydrogels. Polym. Chem. 2016, 7, 418-429. [CrossRef]

20. Zhang, J.; Dumur, F.; Xiao, P.; Graff, B.; Gigmes, D.; Fouassier, J.P.; Lalevéee, J. Aminothiazonaphthalic anhydride derivatives as photoinitiators for violet/blue LED-Induced cationic and radical photopolymerizations and 3D-Printing resins. J. Polym. Sci. Part A Polym. Chem. 2015, 54, 1189-1196. [CrossRef]

21. Xiao, P.; Dumur, F.; Zhang, J.; Graff, B.; Morlet-Savary, F.; Fouassier, J.P.; Gigmes, D.; Lalevée, J. Naphthalic anhydride derivatives: Structural effects on their initiating abilities in radical and/or cationic photopolymerizations under visible light. J. Polym. Sci. Part A Polym. Chem. 2015, 53, 2860-2866. [CrossRef]

22. Xiao, P.; Dumur, F.; Zhang, J.; Graff, B.; Gigmes, D.; Fouassier, J.P.; Lalevée, J. Naphthalimide-phthalimide derivative based photoinitiating systems for polymerization reactions under blue lights. J. Polym. Sci. Part A Polym. Chem. 2014, 53, 665-674. [CrossRef]

23. Zhang, J.; Zivic, N.; Dumur, F.; Xiao, P.; Graff, B.; Gigmes, D.; Fouassier, J.P.; Lalevée, J. A benzophenone-naphthalimide derivative as versatile photoinitiator of polymerization under near UV and visible lights. J. Polym. Sci. Part A Polym. Chem. 2014, 53, 445-451. [CrossRef]

24. Xiao, P.; Dumur, F.; Graff, B.; Gigmes, D.; Fouassier, J.-P.; Lalevée, J. Blue light sensitive dyes for various photopolymeriza-tion reactions: Naphthalimide and naphthalic anhydride derivatives. Macromolecules 2014, 47, 601-608. [CrossRef]

25. Xiao, P.; Dumur, F.; Frigoli, M.; Tehfe, M.-A.; Graff, B.; Fouassier, J.P.; Gigmes, D.; Lalevée, J. Naphthalimide based methacrylated photoinitiators in radical and cationic photopolymerization under visible light. Polym. Chem. 2013, 4, 5440-5448. [CrossRef]

26. Fouassier, J.-P.; Lalevée, J. Recent Advances in Photoinduced Polymerization Reactions under 400-700 nm Light. Photochemistry 2014, 42, 215-232.

27. Dumur, F.; Gigmes, D.; Fouassier, J.-P.; Lalevée, J. Organic Electronics: An El Dorado in the Quest of New Photocatalysts for Polymerization Reactions. Accounts Chem. Res. 2016, 49, 1980-1989. [CrossRef]

28. Dietlin, C.; Schweizer, S.; Xiao, P.; Zhang, J.; Morlet-Savary, F.; Graff, B.; Fouassier, J.-P.; Lalevée, J. Photopolymerization upon LEDs: New photoinitiating systems and strategies. Polym. Chem. 2015, 6, 3895-3912. [CrossRef]

29. Zivic, N.; Bouzrati-Zerelli, M.; Kermagoret, A.; Dumur, F.; Fouassier, J.P.; Gigmes, D.; Lalevée, J. Photocatalysts in Polymeri-zation Reactions. ChemCatChem. 2016, 8, 1617-1631. [CrossRef]

30. Telitel, S.; Dumur, F.; Campolo, D.; Poly, J.; Gigmes, D.; Fouassier, J.P.; Lalevéee, J. Iron complexes as potential photocatalysts for controlled radical photopolymerizations: A tool for modifications and patterning of surfaces. J. Polym. Sci. Part A Polym. Chem. 2015, 54, 702-713. [CrossRef]

31. Xiao, P.; Dumur, F.; Graff, B.; Fouassier, J.P.; Gigmes, D.; Lalevée, J. Cationic and Thiol-Ene Photopolymerization upon Red Lights Using Anthraquinone Derivatives as Photoinitiators. Macromolecules 2013, 46, 6744-6750. [CrossRef]

32. Xiao, P.; Dumur, F.; Graff, B.; Morlet-Savary, F.; Vidal, L.; Gigmes, D.; Fouassier, J.P.; Lalevée, J. Structural Effects in the Indanedione Skeleton for the Design of Low Intensity 300-500 nm Light Sensitive Initiators. Macromolecules 2013, 47, 26-34. [CrossRef] 
33. Lalevée, J.; Blanchard, N.; Tehfe, M.A.; Peter, M.; Morlet-Savary, F.; Gigmes, D.; Fouassier, J.P. Efficient Dual Radical/CationicPhotoinitiator under Visible Light: A New Concept. Polym. Chem. 2011, 2, 1986-1991. [CrossRef]

34. Lalevée, J.; Blanchard, N.; Tehfe, M.-A.; Peter, M.; Morlet-Savary, F.; Fouassier, J.P. A Novel Photopolymerization Initiating System Based on an Iridium Complex Photocatalyst. Macromol. Rapid Commun. 2011, 32, 917-920. [CrossRef] [PubMed]

35. Wang, X.; Bai, X.; Su, D.; Zhang, Y.; Li, P.; Lu, S.; Gong, Y.; Zhang, W.; Tang, B. Simultaneous Fluorescence Imaging Reveals N-Methyl-d-aspartic Acid Receptor Dependent Zn2+/H+ Flux in the Brains of Mice with Depression. Anal. Chem. 2020, 92, 4101-4107. [CrossRef] [PubMed]

36. Foresman, J.B.; Frisch, A. Exploring Chemistry with Electronic Structure Methods. In Exploring Chemistry with Electronic Structure Methods, 2nd ed.; Gaussian Inc.: Pittsburgh, PA, USA, 1996.

37. Frisch, M.J.; Trucks, G.W.; Schlegel, H.B.; Scuseria, G.E.; Robb, M.A.; Cheeseman, J.R.; Zakrzewski, V.G.; Montgomery, J.A.; Stratmann, J.R.E.; Burant, J.C.; et al. Gaussian 03, Revision B-2; Gaussian Inc.: Pittsburgh, PA, USA, 2003.

38. Al Mousawi, A.; Dumur, F.; Garra, P.; Toufaily, J.; Hamieh, T.; Goubard, F.; Bui, T.-T.; Graff, B.; Gigmes, D.; Fouassier, J.-P.; et al. Azahelicenes as visible light photoinitiators for cationic and radical polymerization: Preparation of pho-to-luminescent polymers and use in high performance LED projector 3D printing resins. J. Polym. Sci. A Polym. Chem. 2017, 55, 1189-1199. [CrossRef] 